\title{
LA ACTUALIDAD HERMENÉUTICA DE ARISTÓTELES ${ }^{1}$
}

\section{THE HERMENEUTIC RELEVANCE OF ARISTOTLE}

\author{
Juan de Dios Bares Partal ${ }^{*}$
}

Fechas de recepción y aceptación: 16 de diciembre de 2019 y 4 de junio de 2020

Resumen: El presente artículo pasa revista a las dimensiones hermenéuticas presentes en la filosofía aristotélica, y se detiene en la filosofía

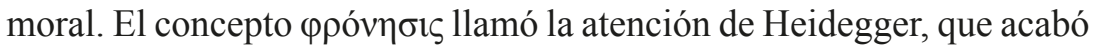
aproximándolo al de conciencia (Gewissen), y de Gadamer, que encuentra en él un modelo de los problemas de la aplicación (Anwendung) en la tarea hermenéutica. El propio Gadamer acabará defendiendo el carácter dialogal y hermenéutico de la retórica, que no es más que una

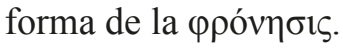

Palabras clave: hermenéutica, prudencia, conciencia, acción moral, aplicación.

Abstract: This article reviews the hermeneutical dimensions present in Aristotelian philosophy, and focuses on moral philosophy. The concept of "prudence" caught the attention of Heidegger, who brought it close to that of "conscience" (Gewissen), and Gadamer, who finds in

${ }^{a}$ Facultat de Filosofia i Ciències de l'Educació. Universitat de València.

${ }^{*}$ Correspondencia: Universitat de València. Facultat de Filosofia i Ciències de l'Educació. Avenida Blasco Ibáñez, 30. 46010 València. España.

E-mail: juan.d.bares@uv.es

${ }^{1}$ Este trabajo ha surgido en el marco del proyecto de investigación "Historia conceptual y crítica de la modernidad" (FFI2017-82195-P) de la AEI/FEDER, UE. 
this concept a model of the problems of application (Anwendung) in the hermeneutical task. Gadamer himself will later defend the dialogic and hermeneutical character of rhetoric, which is nothing but a form of

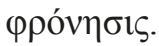

Keywords: hermeneutics, prudence, conscience, moral action, application.

\section{§1. Introducción. Dimensiones hermenéuticas DE LA FILOSOFÍA ARISTOTÉLICA. LA MORAL}

El término hermenéutica alude a una doctrina, una práctica o una teoría de la interpretación. Designa un ámbito que se ha vuelto especialmente importante en la modernidad, entendida como una teoría de la interpretación de textos. Es cierto que las señas de identidad de la moderna hermenéutica anclan en los problemas de interpretación de la Biblia en el contexto de la pugna entre el protestantismo y el catolicismo. Sin embargo, los problemas de la interpretación no son desconocidos en épocas anteriores. En la antigüedad clásica la mayor parte de los asuntos de los que se ocupa la hermenéutica actual estaban incluidos dentro de la retórica y la poética, disciplinas en las que la reflexión aristotélica alcanza una especial profundidad.

De hecho, hermenéutica, como es bien sabido, es una palabra griega. En Homero, el $\dot{\varepsilon} \mu \eta \eta v \varepsilon u ́ \varsigma$ era el intérprete de los dioses. Desde tiempos remotos esta palabra está vinculada con el dios Hermes, mensajero de los dioses. En

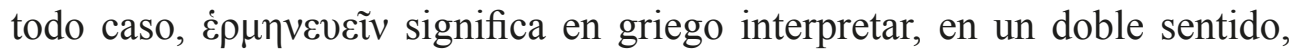
como transmisión de un contenido, comunicación, pero también con una carga nomológica: un mandato. El intérprete media, transmite y explica el sentido de lo que está oscuro².

${ }^{2}$ Sobre la historia y las raíces del término hermenéutica, Gadamer realiza un magnífico recorrido por el sentido del término y su historia (Hermenéutica clásica y hermenéutica filosófica (1977), en Gadamer, 1998: $95 \mathrm{ss}$ ). En nota se hace eco de que la filología más reciente entonces (Benveniste) pone en duda que la etimología de esta palabra tenga que ver con el dios Hermes. En cualquier caso, así lo creían los antiguos. 
Aristóteles compuso una obra que lleva el título de $\pi \varepsilon \rho \grave{\varepsilon} \dot{\rho} \mu \eta v \varepsilon i ́ \alpha \varsigma$, que se tradujo al latín como De Interpretatione y que se suele titular en castellano Acerca de la interpretación. El título puede resultar algo equívoco para un lector moderno, porque no es un tratado de teoría de la interpretación en el sentido actual del término ni un conjunto de reglas hermenéuticas. Se trata de un escrito que se ocupa de lo que hoy llamaríamos aspectos semánticos de la lógica aristotélica. Aunque no se atiene al concepto de hermenéutica que emplea la tradición moderna, ciertamente sus primeras páginas establecen una poderosa teoría del símbolo, de la estructura del lenguaje y el significado que es fundamental para cualquier desarrollo posterior en los ámbitos tanto lógico y lingüístico como propiamente hermenéutico. Gadamer afirma con razón que en el $\pi \varepsilon \rho \grave{~} \dot{\rho} \mu \eta v \varepsilon i ́ a \varsigma$ atendemos solamente a una representación

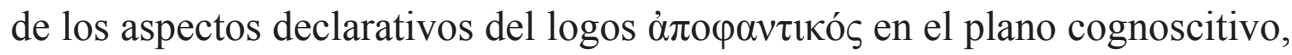
que es un camino ampliamente frecuentado por nuestra tradición filosófica ${ }^{3}$.

Siendo importante, desde luego, ese punto no deja de ser la punta del iceberg. El propio Gadamer reconoce que la moderna hermenéutica se nutre de la antigua tradición retórica que ya había desbrozado importantes cuestiones relativas a los problemas de la interpretación. Aunque existieron tratados de retórica anteriores a Aristóteles, y aunque Platón abordó con gran profundidad estos temas, es Aristóteles el primero que nos dotó de un tratado de retórica sistemático. En él se establece el objetivo de esta disciplina. La retórica tiene por objeto producir convicción en el oyente y aborda por lo tanto cuestiones vinculadas con la expresión y el contenido de los argumentos -la $\lambda \dot{\varepsilon} \xi 1 \varsigma$ - en una dirección muy próxima a la de la dialéctica, ciencia de la argumentación probable. Atendiendo a lo que hoy llamaríamos la situación hermenéutica, define tres tipos básicos de retórica que requiere cada una de ellas su género, estilo y contenido peculiares: la retórica forense, la deliberativa y la epidíctica. En su tratamiento tiene en cuenta las condiciones del auditorio y las circunstancias. La autoridad y la respetabilidad del orador obtienen también

3 "Resulta significativo para el otro componente semántico puramente cognitivo que Aristóteles en el escrito Peri hermeneias se refiera solo al sentido lógico del enunciado cuando aborda el logos apophantikos. En esa línea se desarrolla en el mundo griego posterior el sentido puramente cognitivo de hermeneia y hermeneus, y puede significar «explicación docta» o «comentador»y «traductor»" (Gadamer, 1998: 96). 
el reconocimiento a su importancia, y se rescatan los importantes rasgos de la retórica gorgiana del kaıpós. Entender la comunicación y la comprensión de lo comunicado en un contexto en el que interaccionan personas en condiciones diversas que pueden afectar a la comunicación lleva a Aristóteles a abordar en el libro segundo de esta obra un muy logrado análisis de las pasiones que pueden afectar al auditorio, para extraer de ello enseñanzas sobre cómo se puede influir en ellos. En el resto de la obra es interesante su estudio del argumento retórico -el entimema-, equiparable a un silogismo incompleto en el que lo que importa es su fuerza de convicción, así como de otros recursos de argumentación persuasiva como el ejemplo y la máxima. El estudio de las figuras de dicción que se realiza a lo largo del libro tercero consigue un análisis tan logrado de los diferentes tropos y figuras retóricas que ha pasado a los manuales de gramática y estilo de todos los tiempos. Destaca allí el tratamiento de la metáfora como traslación de significado, punto en el que Ricoeur (1980) cree que radica la posibilidad de significación del lenguaje. También, entre los filósofos de habla hispana, Mauricio Beuchot ${ }^{4}$ confiere gran importancia al concepto de analogía aristotélico en la forma en que es tratado en la retórica. Como veremos a lo largo de este trabajo, el último Gadamer reivindicará también enérgicamente el carácter hermenéutico de la retórica aristotélica.

También se encuentran importantes elementos retóricos en la Poética de nuestro autor. Se trata de un texto de crítica literaria, el primero que conocemos que intenta sistematizar el estudio de la epopeya, la tragedia y -presumiblemente también- la comedia. El tratado rebasa con creces el campo del análisis estilístico de la obra literaria para adentrarse en una decidida defensa de la obra de arte creativa centrada en el concepto de mímesis que forjó Platón con la intención opuesta de denigrar la obra del artista. La imitación -tal vez sería más apropiado denominarla "representación"- y el concepto ligado a él de verosimilitud permiten integrar conceptualmente el tipo de obras que constituyen lo que hoy llamaríamos ficción. De este modo, presenta una definición de la tragedia entendida como una "síntesis de acciones". El propio

\footnotetext{
${ }^{4}$ El propio Beuchot realiza un interesante recorrido por esta obra de Aristóteles subrayando los aspectos hermenéuticamente relevantes. Encuentra especialmente importante el tratamiento aristotélico de la noción de analogía (Beuchot, 2007).
} 
Ricoeur dedica el primer volumen de su Temps et récit a explorar la rentabilidad hermenéutica de tal análisis (Ricoeur, 1987).

Estas son algunas de las bien conocidas direcciones que adopta la filosofía aristotélica y que resultan plenamente válidas como líneas de confluencia con la moderna hermenéutica. Todas ellas hacen patente la riqueza del planteamiento del Estagirita. Aun así, en este punto cabe decir que no tenemos la intención de restringir solamente a ellas, ni mucho menos, la herencia aristotélica.

En lo que sigue vamos a dedicarnos con especial detenimiento a una aportación hermenéutica de la obra aristotélica tal vez oculta a primera vista y que posiblemente ha acabado por ser la más central, al menos en el siglo $\mathrm{xx}^{6}$. Se trata de la dimensión hermenéutica de la filosofía moral aristotélica, y en

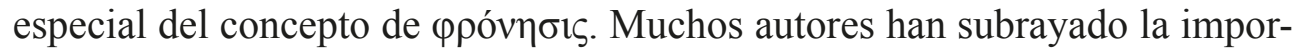
tancia de este concepto y su cercanía o paralelismo al concepto moderno de comprensión. En cualquier caso, la reflexión sobre la acción moral en la ética del Estagirita ha ayudado a emancipar a las ciencias humanas de los estrechos cauces del conocimiento teórico universalista propio de la ciencia y la teología occidentales. A fin de cuentas, la retórica, la creación literaria y las demás

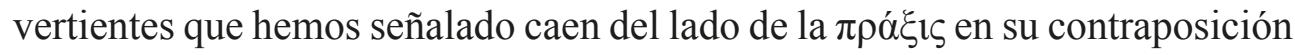
con la $\theta \varepsilon \omega p i ́ a$ y no dejan de ser exponentes de modos de acción práctica.

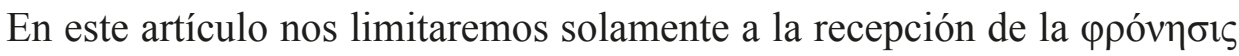
aristotélica en Heidegger y Gadamer, lo cual es, claro está, solamente una parte limitada del panorama.

\section{§2. HeIDEGGER: LA ФPONHEII EN EL CONTEXTO DE UNA HERMENÉUTICA DE LA FACTICIDAD}

Las indagaciones del primer Heidegger en los años anteriores a Ser $y$ Tiempo están nutridas por un cruce de múltiples intereses desde los estudios

\footnotetext{
${ }^{5}$ Un tratamiento sobre el tema en De Haro (2002).

6 "Se admite que el libro VI de la Ética a Nicómaco es el libro más leído y citado del pensamiento europeo desde los años cincuenta del pasado siglo hasta la fecha" (Oñate, 2007: 55). La autora lo menciona con cierto disgusto, toda vez que cree que sin la Metafísica la filosofía moral de Aristóteles no puede ser bien comprendida.
} 
históricos de la lógica medieval y moderna hasta la teología y sus consecuencias ontológicas, junto con la importante veta husserliana y fenomenológica. Todo ello irá cristalizando en la obra mayor de nuestro autor en una potente indagación sobre la temporalidad como elemento constitutivo de la existencia humana, realizada esta por una preocupación ontológica, una necesidad, como se indica en el principio de su obra, de volver a plantear la pregunta por el ser ${ }^{7}$. Para poder desplegar la ontología fundamental prevista, Heidegger necesita previamente realizar una analítica existencial del Dasein, el único ente al que le va su ser. Heidegger plantea recorrer este camino con la metodología de una hermenéutica fenomenológica de inspiración husserliana. Este proceder tiene una vertiente negativa, la célebre destrucción, y otra positiva, el análisis efectivo de las categorías existenciales que constituyen el ser ahí.

Aristóteles vale para Heidegger como modelo culminante de la ontología antigua. Hereda la importante interpretación de Brentano ${ }^{8}$ y entiende que el núcleo de la aportación ontológica aristotélica reside en la relación entre el ser y las categorías, y la subsiguiente doctrina de la analogía. Dado que el horizonte donde se va a plantear la pregunta por el ser es el tiempo, saluda también como un logro muy positivo la interpretación que brinda de este el Estagirita en las páginas de su Física. Heidegger minusvalora los análisis de la Física y restringe su importancia a un estudio de la dimensión natural del tiempo que muestra magistralmente su conexión con el movimiento, pero que ignora las estructuras existenciales fundamentales que lo componen, puesto que estas solamente podrían alcanzarse, a su juicio, desde una analítica existenciaria previa al ser ahí (Heidegger, 1971: 454).

En la parte crítica de la obra, en la famosa Destruktion, el objetivo fundamental de crítica es la concepción cartesiana del sujeto como sustancia. El sustancialismo aristotélico es asimismo la posición paradigmática de la ontología antigua y es elogiado y señalado al mismo tiempo como el exponente de una visión ya desviada que obstaculiza una vuelta a las cosas mismas. Toda

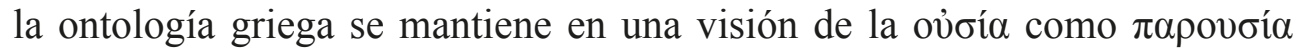

\footnotetext{
${ }^{7}$ Heidegger (1971: 10). Cf. la famosa cita de Sofista 244 que sirve de Pórtico a la obra.

${ }^{8}$ A Heidegger le impresionó desde temprano la obra de Brentano De la múltiple significación del ser en Aristóteles. Sobre la relación entre nuestro autor y Brentano, véase Volpi (1976). El conocimiento de la obra aristotélica también pudo venirle a Heidegger en Friburgo de la relación con Carl Braig.
} 
(Heidegger, 1971: 35). Lo mismo sucede en el ámbito de la lógica y la verdad: Aristóteles es el supuesto escaparate de una concepción del logos como predicación que asigna el lugar de la verdad al enunciado y al lenguaje predicativo.

Heidegger señala que Aristóteles no restringe el papel de la verdad, en realidad, al enunciado 9 , pero deja en esta obra en suspenso cualquier otra consideración.

Hay también en el texto interesantes alusiones a la Metafísica, el De Ani$m a$, la Retórica, la Física. Aunque no es ignorado, su presencia no es masiva ni determinante. Si tuviéramos que evaluar el influjo aristotélico sobre el filósofo alemán a juzgar por los efectos que se aprecian en Ser y tiempo, no podríamos sino considerarlo una influencia entre otras.

El panorama cambia cuando atendemos los cursos y escritos que Heidegger impartió y redactó en los años veinte y que le llevaron a la composición de su obra maestra. En ellos constatamos que nuestro pensador se dedicó extensivamente a comentar determinadas partes de la obra aristotélica de la que extrajo importantes claves para la fijación de su propia posición filosófica. La cantidad de seminarios y cursos dedicados a Aristóteles es impresionante. Baste como muestra la relación que da Volpi solamente de los cursos de Friburgo:

De la lista de seminarios y cursos que tuvo a su cargo podemos deducir la frecuencia con que Heidegger se ocupa de Aristóteles: en el semestre de verano de 1916 dicta junto con Krebs un seminario acerca de pasajes escogidos de los escritos lógicos de Aristóteles; en el semestre de verano de 1921 (paralelamente a un curso sobre Agustín y el neoplatonismo) lee en un seminario práctico el De anima; en el semestre de invierno de 19211922 dicta un curso sobre la Física (anunciado ahora en HGA LXI con el título Phänomenologische Interpretation zu Aristoteles $)^{10}$; en el semestre de verano de 1922, una vez más, un curso completo sobre pasajes escogidos de la ontología y de la lógica de Aristóteles y además, paralelamente, un seminario sobre la Ética a Nicómaco; por último, en el semestre de

\footnotetext{
${ }^{9}$ Heidegger (1971: 449). Este es un tema importante para poder abordar una concepción ontológica de la verdad como desvelamiento. Más abajo veremos que en sus cursos nuestro filósofo se había ocupado de este tema.

${ }^{10}$ Se trata del Informe Natorp, del que nos ocuparemos a continuación, publicado finalmente en el volumen 62 de la Gesamtsausgabe.
} 
invierno de 1922-1923 dicta un seminario acerca de los libros IV y V de la Física ${ }^{11}$.

También fue bastante intensa la confrontación con la obra de Aristóteles en los primeros cursos, hasta mediados de los años veinte, en Marburgo, donde destacan el curso del semestre de invierno de 1924-25 sobre el Sofista, del que nos ocuparemos más abajo, o el semestre de verano de 1925 publicado con el título Prolegómenos para una historia del concepto de tiempo. Allí se estudian cuestiones ontológicas comunes al planteamiento husserliano y aristotélico, y se desafían las tesis de que el lugar de la verdad sea la proposición y que Aristóteles haya defendido la verdad como adaequatio que luego aparecerán en Ser y Tiempo.

Vamos a referirnos a un texto, no de las lecciones de Heidegger, sino compuesto y escrito por él mismo, aunque no destinado directamente a publicación. Se trata del famoso dossier añadido a la documentación presentada para optar a una plaza en la Universidad de Marburgo. Este escrito fue compuesto por Heidegger a instancias del profesor Paul Natorp, para dar a conocer los resultados de su labor filosófica ${ }^{12}$, dado que sus publicaciones eran hasta la fecha escasas. Se trata de un texto valiente, toda vez que se sitúa en las antípodas del pensamiento kantiano prevalente en Marburgo y reclama una reivindicación de la vuelta a Aristóteles desde las coordenadas de una ontología fenomenológica. Es un escrito importantísimo para comprender en toda su profundidad Ser y tiempo y los planteamientos básicos del primer Heidegger. Haremos a continuación una breve sinopsis de su planteamiento y comenta-

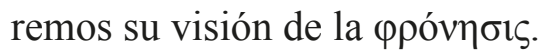

Comienza el autor señalando la importancia, en la interpretación, de la situación hermenéutica de la que depende. Esta situación nos permite poner de relieve el punto de mira, la dirección de la mirada y el horizonte de esta

${ }^{11}$ Volpi (2012: 73). En Segura (2002: 164 ss) encontramos un anexo con un completo índice de las publicaciones, lecciones y cursos de Heidegger anteriores a 1927.

${ }^{12} \mathrm{El}$ texto es conocido como Informe Natorp. Su título es Interpretaciones fenomenológicas sobre Aristóteles (indicación de la situación hermenéutica). La traducción española es de Jesús Adrián Escudero. La introducción al texto de este autor en Heidegger (2002) es valiosa, así como la monografía de Carmen Segura (2002). Segura aborda también el tema desde el contexto del conjunto de la producción temprana de Heidegger en Segura (2014). Cf. tb. Bertorello (2000). 
para así poder ubicar la pretensión de objetividad de toda interpretación. Solamente desde una situación hermenéutica determinada, desde su resolución y capacidad de apertura, resulta posible un acceso fructífero al pasado. La investigación filosófica que se despliega en esa situación es una indagación del carácter ontológico de la existencia humana, siempre traspasada por la facticidad. La comprensión, el cuidado, el mundo y la propia existencia humana, el Dasein y la importancia de la temporalidad y la muerte son ingredientes importantes de la trama teórica de Ser y Tiempo que sirven ya en este escrito para enmarcar el recurso al pasado. Todo ello lleva a una ontología fundamental que es al mismo tiempo una lógica y, en suma, una fenomenología que tiene por norte una hermenéutica fenomenológica de la facticidad. El fenómeno de la facticidad va unido al de la caída y al carácter dinámico de la propia actividad filosófica. Es por ello que debemos atender a lo que no está expreso y se da por supuesto en la interpretación para poder apropiárnoslo. Esta tarea asume la forma negativa de la destrucción, herramienta crítica fundamental para poder retrotraernos al pasado:

Así, los proyectos de una lógica radical del origen y las primeras contribuciones a la ontología se esclarecen de una manera fundamentalmente crítica. La crítica que resulta de la simple realización concreta de la destrucción no tiene nada que ver con el hecho de que nos encontremos por lo general en una tradición, sino en la manera como nos encontramos en ella. Aquello que no logramos interpretar y expresar de un modo originario, no sabemos custodiarlo en su autenticidad ${ }^{13}$.

Heidegger cree que, con respecto a la facticidad, nuestra cultura se mueve en las coordenadas de una interpretación grecocristiana de la vida y le resulta por ello necesario abordar en profundidad los puntos de inflexión de su decurso histórico: Lutero, San Pablo, San Agustín, la escolástica, Pedro Lombardo, el neoplatonismo. Dentro de esta mirada retrospectiva, Aristóteles reviste una significación nodal. La filosofía aristotélica resulta un peldaño ineludible para la realización de una antropología fenomenológica, porque a partir de su física cudero.

${ }^{13}$ Heidegger (2002: 21). La traducción de los textos que cito de esta obra es de Jesús Adrián Es- 
es capaz de situar a la ontología y a la lógica tras la pista de un fenómeno fundamental, en cuya consideración radica la capacidad de abordar una concepción dinámica de la realidad: el fenómeno central, cuya explicación constituye el tema de la física, es el ente en el cómo de su ser-movido. Aristóteles posibilita una antropología filosófica porque ha proporcionado una ontología dinámica. Por eso es el concepto de ser la gran contribución de su pensamiento.

Heidegger visitará algunos pasajes de la obra aristotélica para detallar su explicación. Entre otros, resultan especialmente relevantes el libro VI de la Ética a Nicómaco, los dos primeros capítulos del libro A de la Metafísica, así como los tres primeros libros de la Física hasta la definición del movimiento. Heidegger siempre subrayará la importancia de la concepción del movimiento y del ser en movimiento que alcanza su cumbre en los libros centrales de la Metafísica. No vamos a seguirle, sin embargo, en todo su recorrido, porque reflejar lo importante que es Aristóteles en la tradición filosófica occidental no es el objeto de nuestro trabajo, sino determinar qué aspectos propiamente hermenéuticos podemos encontrar en el pensamiento aristotélico, y para esa tarea creemos que el hecho realmente relevante es reparar en la reflexión heideggeriana sobre el libro VI de la Ética a Nicómaco.

¿Por qué resulta tan importante para la hermenéutica el análisis que hace Heidegger de unos pasajes de la Ética? Porque en ellos Aristóteles se muestra capaz de ampliar el ámbito de la verdad y de la comprensión de la realidad más allá del mero tener ante los ojos de la actitud teórica y diseña un modelo de comprensión que opera en la praxis. Aun cuando él mismo no extraiga todas las consecuencias que ello supone, libera una importantísima herramienta

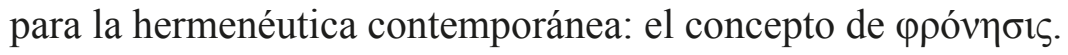

Heidegger cita el comienzo del capítulo tercero del libro VI de la Ética a Nicómaco:

Establezcamos, pues, que son cinco los modos -y esto vale tanto para la afirmación como para la negación- por los cuales el alma tiene y toma en custodia el ente en cuanto desvelado: el proceder técnico-productivo

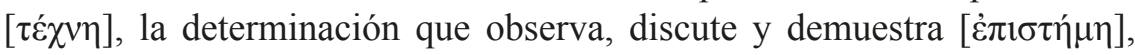

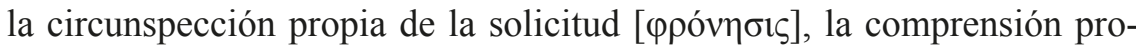
piamente intuitiva [бopía], el inteligir puro [voũs] (Heidegger, 2002: 29). 
Estamos en el ámbito de las virtudes dianoéticas, disposiciones estables del alma [ $\left.{ }^{\mathscr{\varepsilon}} \xi \varepsilon 1 \zeta\right]$ relativas, no a nuestra actitud con respecto a los placeres y los dolores, o nuestra tendencia a actuar de un modo u otro, sino relativas a la verdad, tanto en el plano de la acción, como en el del conocimiento mismo. El alma, en cada una de estas actitudes posee la verdad (lo que Heidegger llama "custodiar la verdad del ente en cuanto desvelado") al afirmar o negar.

Heidegger rechaza, de acuerdo con este texto, que la verdad sea una propiedad exclusiva de los juicios, y mucho menos que consista en una pretendi-

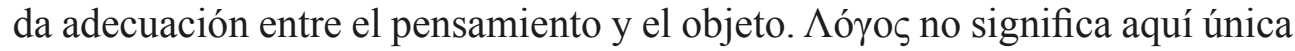
ni preponderantemente "juicio". A $A \lambda \eta \dot{\theta} \varepsilon \alpha$ hace referencia a la desocultación o desvelamiento del ser, y poseer la verdad es hacerse cargo y custodiar ese desvelamiento ${ }^{14}$.

Lo que más le interesa a nuestro pensador de este importante texto, más allá de la técnica y la ciencia, son los tres últimos elementos: la prudencia (que él denomina "circunspección propia de la solicitud"), la sabiduría (para él, "comprensión propiamente intuitiva"), y "el inteligir puro". Lo fundamen-

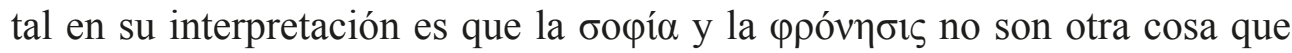
"modalidades específicas en las que se realiza el voũ $\varsigma$ " (Heidegger, 2002: 29). El voũ s es una aprehensión inmediata a nivel inteligible, semejante a la percepción sensible misma, que es también inmediata y no susceptible de error cuando se trata de los sensibles propios en las condiciones adecuadas. Afirma, parafraseando un texto del De Anima ${ }^{15}$, que el alma es como una luz, y proporciona el horizonte veritativo en el que nos son dados los entes:

El intelecto, al igual que la luz, produce todas las cosas en la medida en que permite disponer de ellas. El voũ $̧$ ofrece en general una perspectiva, da algo, proporciona un "aquí" (Heidegger, 2002: 33).

14 "Según Heidegger, como queda señalado de manera paradigmática en el parágrafo 44 de Ser y tiempo, se ha atribuido a Aristóteles habitual e injustamente la tesis de que la verdad es adecuación entre pensamiento y objeto y que su lugar está en los juicios, pero su interpretación es distinta. Ya en el Informe Natorp, va a insistir en que verdad para Aristóteles es desvelamiento $(\dot{\alpha} \lambda \hat{\eta} \theta \varepsilon 1 \alpha)$, y en que por tanto no es una propiedad de los juicios, sino de los entes en su desvelarse y simultáneamente ser desvelados. Por eso, en la interpretación que hace de Aristóteles no considera que la proposición sea el lugar en que se da primariamente la verdad, sino que la verdad es el «lugar» de la proposición” (Segura, 2007: 39).

${ }^{15} \Gamma, 5,430^{\mathrm{a}} 15$. 
Pero el intelecto es, como la percepción sensible, inmediato, no tiene la posibilidad de ser falso ni la articulación propia de la enunciación. Es el prin-

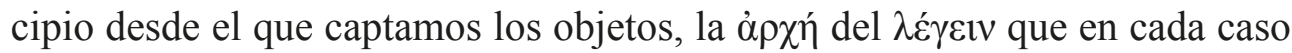
se despliega a partir de él. En este sentido, la intelección es la que mantiene los principios en cada ámbito ontológico, y por eso afirma de ella Gadamer

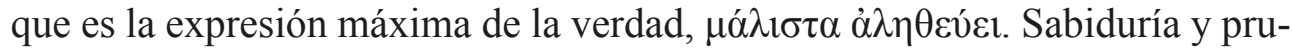
dencia parten de ella, pues anclan en los principios, es más, son modalidades de ella:

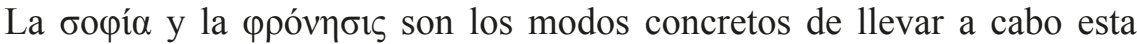
custodia auténtica del ser en la verdad. El puro comprender contemplativo custodia el ente y el "a-partir-de-dónde" del ente que tiene la característica de ser siempre y necesariamente lo que es. En cambio, la circunspección solícito-discursiva custodia un tipo de ente que en sí mismo puede ser distinto de su "a-partir-de dónde" (Heidegger, 2002: 34).

Esto es, la sabiduría ("el puro comprender contemplativo") se desarrolla como un saber de lo que es siempre y es necesario, mientras que la prudencia ("la circunspección solícito-discursiva") se dirige a lo particular, mudable y cambiante. Nos desentendemos ahora de la sabiduría. Es, sí, el más elevado y noble de los saberes, el saber acerca de las cosas divinas, y posiblemente la más alta aspiración del hombre. Pero no nos sirve para comprendernos a nosotros mismos, ni nuestra vida, ni el mundo que nos rodea. Es incompatible con la facticidad que atraviesa la existencia humana y la constituye. Por eso, el saber propiamente humano, en el que radicarán la comprensión y la interpretación, será el saber práctico capaz de hacerse cargo del hombre y de su acción:

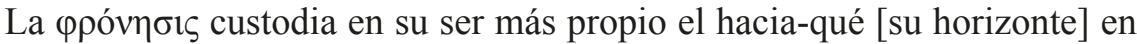
que se despliega el trato que la vida humana mantiene consigo misma, así como el modo de llevar a la práctica ese trato. La $\pi \rho \alpha ́ \xi \xi \varsigma$ es un trato de este tipo: el trato que simplemente actúa, el trato que no responde al modo de la producción, sino que única y exclusivamente obedece al criterio de la $a c$ -

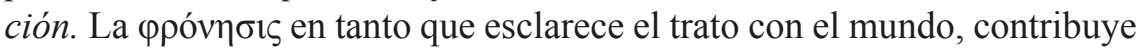
al despliegue temporal de la vida en su ser (Heidegger, 2002: 35). 
La prudencia es el corazón de la vida fáctica, aquella disposición que nos permite apropiárnosla, asumirla y hacernos cargo de ella, dirigiendo nuestra acción:

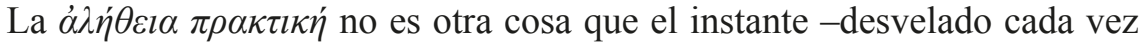
en su plenitud- en el que la vida fáctica está decididamente predispuesta a habérselas consigo misma, y ello en el contexto de una relación fáctica de la preocupación por el mundo que en ese mismo instante le sale al encuen-

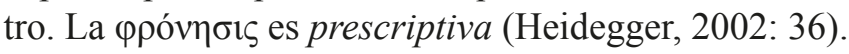

A pesar de la dimensión que toman estas afirmaciones a la luz de desarrollos posteriores en la teoría hermenéutica, su alcance en el Informe Natorp es

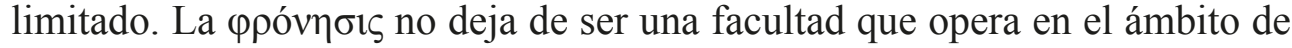
la circunspección, del mirar en torno, que opera de manera negativa, que no sale del estar referido a y de la realización de tareas concretas.

Será años más tarde cuando Heidegger comience a advertir el tremendo potencial de esta noción aristotélica. En su seminario sobre el Sofista en 192425 da un paso más:

Asimismo, respecto de la $\varphi \rho o ́ v \eta \sigma \iota \varsigma$ no hay ningún olvido $(\lambda \dot{\eta} \theta \eta): \sigma \eta \mu \varepsilon \tilde{\imath} o v \delta^{\prime}$

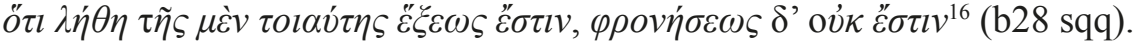
En la $\varphi \rho o ́ v \eta \sigma \iota \varsigma$ no se da la posibilidad de caída del olvido. Ciertamente, la explicación que proporciona aquí Aristóteles es muy sucinta. Pero queda claro a partir del contexto que no es ir demasiado lejos en la interpretación decir que Aristóteles se ha topado aquí con el fenómeno de la conciencia. La $\varphi \rho o ́ v \eta \sigma ı \varsigma$ no es otra cosa que la conciencia puesta en movimiento que realiza una acción mirando a través. La conciencia no se puede olvidar. Sin embargo, se puede trastocar y volver inefectivo mediante el placer y el dolor aquello que la conciencia descubre. La conciencia siempre vuelve a presentarse ${ }^{17}$.

16 "Señal de ello es que hay olvido de esta disposición -se refiere a la sensación-. Sin embargo, no la hay de la prudencia".

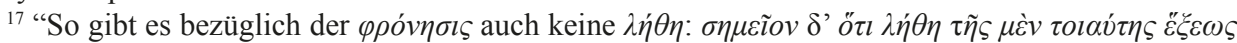

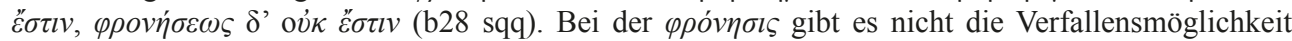
des Vergessens. Zwar ist die Explikation, die Aristoteles hier gibt, sehr knapp. Aber es ist doch aus dem Zu-sammenhang deutlich, daß man in der Interpretation nicht zu weit geht, wenn man sagt, daß 
La $\varphi \rho o ́ v \eta \sigma ı \varsigma$ se ve identificada aquí con la conciencia (Das Gewissen). La conciencia no es en Heidegger mera reflexión, sino que tiene una importante virtualidad fáctica. Aparece en Ser y Tiempo vinculada al "tener que ser" y a la resolución La toma de conciencia lleva al Dasein del "se" impersonal e inauténtico a decidirse por su propio tener que $\operatorname{ser}^{18}$.

Al parecer, Heidegger debió de repetir en la primera parte de su curso de 1924 en Marburgo los resultados de su seminario en Friburgo del año anterior. Estas palabras fueron captadas por un inteligente discípulo, asistente a aquel curso, que muchos años después seguía recordando el comentario de su

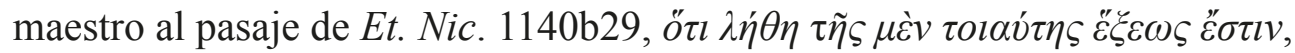

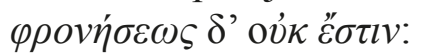

Cuando intentamos interpretar esta frase, muy inseguros y con una alienación mental totalmente situada en los términos griegos, él declaró en tono brusco: “¡Esto es la conciencia!”. Aquí no hay lugar para reducir a su justa dimensión la exageración pedagógica que había en esta afirmación, y menos aún para mostrar la presión lógica y ontológica que pesaba en realidad sobre el análisis de la phronesis en Aristóteles. Hoy está claro lo que Heidegger encontró en ella y por qué la crítica aristotélica a la idea platónica del bien y el concepto aristotélico del saber práctico le fascinaron tanto: en ellos se describía una forma de saber (un عĩ்o $\gamma v \omega ́ \sigma \varepsilon \omega \varsigma$ ) que ya no se podía referir a una objetivabilidad última en el sentido de la ciencia, pues era un saber en la situación existencial concreta. ¿Era posible que Aristóteles incluso podría ayudar a superar los prejuicios ontológicos del concepto griego de logos, que Heidegger interpretaría más tarde en sentido temporal como ser-a-la-vista [Vorhandenheit $]$ y presencia? ${ }^{19}$

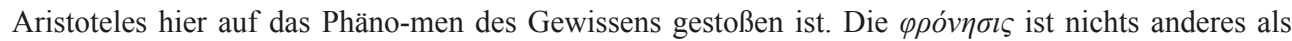
das in Bewegung gesetzte Gewissen, das eine Handlung durchsichtig macht. Das Gewissen kann man nicht vergessen. Wohl aber kann man das, was das Gewissen aufdeckt, durch $\dot{\eta} \delta o v \dot{\eta}$ und $\lambda \dot{v} \pi \eta$, durch Leidenschaften, verstellen und unwirk-sam werden lassen. Das Gewissen meldet sich immer wieder" (Heidegger, 1992: 56).

${ }^{18}$ Volpi (2012: 110-111).

${ }^{19}$ Gadamer: La teología de Marburgo, en Herder, Los caminos de Heidegger, 2003, p. 43. 


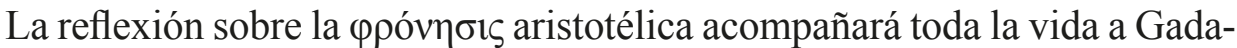
mer. En sus primeros trabajos, Saber práctico, ya se ocupaba de esta cuestión ${ }^{20}$.

La importancia de la equiparación que hemos mencionado la advierte también de inmediato Franco Volpi. Subraya su paralelismo con Das Gewissen, la conciencia moral que permite orientar al Dasein a la autenticidad y está en la base de la resolución. Esta última, como apunta Volpi, tendría también su correlato en la elección:

La correspondencia entre el Gewissen y la phrónesis que Heidegger comprueba no parece ahora del todo injustificada. Así como la conciencia orienta al ser-ahí hacia la autenticidad de elegirse a sí mismo, la phrónesis representa para Aristóteles el saber práctico que es capaz de guiar las acciones y las elecciones del hombre en un sentido moralmente bueno, dirigiéndolo hacia el buen vivir, hacia la mejor forma de vida. Además, esta correspondencia queda confirmada por el análisis de una ulterior determinación que está esencialmente vinculada a la conciencia y que es la resolución (Volpi, 2012: 111).

Esta conciencia práctica y libre de las impostaciones de una metafísica de la presencia se convertirá en Gadamer en un punto fundamental de su teoría de la comprensión.

\section{§3. GADAMER: APLICACIÓN, EXPERIENCIA HERMENÉUTICA Y COMPRENSIÓN}

El título de este trabajo, "La actualidad hermenéutica de Aristóteles", es un conocido epígrafe de Verdad y método, tan interesante como sorprendente en la estructura de la obra.

Después de plantear la historicidad de la comprensión como principio hermenéutico, y diseñar las importantes nociones de círculo hermenéutico,

20 "Los primeros textos de mi proceso intelectual acaban de publicarse por primera vez, en el tomo V de esta edición, bajo el título de Saber práctico (escrito el año 1930). Allí indagué la esencia de la phronesis en estrecha relación con el libro sexto de la Ética a Nicómaco, bajo el estímulo de Heidegger. En Verdad y método I este problema pasa a primer plano" (Gadamer, 1998: 28-9). 
prejuicio, autoridad, tradición y Wirkungsgeschichte, Gadamer se vuelve hacia la hermenéutica para determinar su objeto. El título del capítulo destinado a ello reza: "Recuperación del problema hermenéutico fundamental". En realidad, es el escalón preparatorio del siguiente, "Análisis de la conciencia de la historia efectual", auténtico punto arquimédico de la obra, donde se hace residir en el diálogo la estructura de la experiencia hermenéutica, y se asienta la primacía hermenéutica de la pregunta. Este capítulo previo es tal vez más claro en su rotundo enunciado que en su contenido.

Gadamer parece estar buscando una armonía entre las diferentes facetas de la hermenéutica y también entre los ámbitos en los que se ha desplegado. Menciona la distinción que aparecía en las Institutiones Hermeneuticae Sacrae, de Rambach, entre subtilitas intelegendi, explicandi y applicandi. Afirma que es en la hermenéutica romántica donde habrían sido aunados intelligere y explicare:

La interpretación no es un acto complementario y posterior al de la comprensión sino que comprender es siempre interpretar, y en consecuencia la interpretación es la forma explícita de la comprensión (Gadamer, 1977: 378).

No está claro en qué sentido entiende el autor tal unidad de interpretación y comprensión, que en todo caso es el núcleo del círculo hermenéutico heideggeriano. Añade que es preciso reivindicar la importancia de la Anwendung, la aplicación. Esta consiste en la adaptación del sentido del texto al contexto, a la situación concreta.

La aplicación se reivindica como un momento esencial a todo proceso de comprensión ${ }^{21}$. Esto es especialmente patente en la hermenéutica religiosa, y más aún en la jurídica. Pero la hermenéutica filológica, o si se quiere "espiritual-científica", es también histórica, es un acontecimiento. Al igual que comprender la ley es saber aplicarla, o al menos no podremos aplicarla sin entenderla, y Gadamer entiende que constituyen un proceso unitario, también en la hermenéutica histórica es pertinente hablar de aplicación:

21 "Pensamos por el contrario que la aplicación es un momento del proceso hermenéutico tan esencial e integral como la comprensión y la interpretación" (Gadamer, 1977: 379). 
También la hermenéutica histórica tiene que llevar a cabo una cierta aplicación, pues también ella sirve a la validez de un sentido en la medida en que supera expresa y conscientemente la distancia en el tiempo que separa al intérprete del texto, superando así la enajenación de sentido que el texto ha experimentado (Gadamer, 1977: 383).

En el punto siguiente, cuyo epígrafe da título a nuestro artículo, Gadamer da un paso más y hace consistir la comprensión en aplicación, llegando a sostener que la comprensión sería un caso particular de aplicación (ídem). Se trata de poner en relación algo general con una situación concreta. Los conceptos de tradición y de situación hermenéutica avalan este paso. Ahora bien, la mejor manera de analizar el ejercicio de la comprensión concreta en lo particular se encuentra sin duda en el tratamiento de la prudencia en la Ética a Nicómaco de Aristóteles. Bien entendido, en esta obra el Estagirita no se propone realizar una teoría de la interpretación, ni mucho menos profundizar en la dimensión histórica de la comprensión, sino comprender la naturaleza y el proceder del actuar moral en cuanto racional (Gadamer, 1977: 383). La crítica a la idea del Bien platónica le lleva a desligar la acción humana de principios metafísicos y contemplarla desde lo particular y la determinación. Se abandona la posibilidad de construir un discurso sobre el bien en sí, y se renuncia al intelectualismo moral. En su lugar tenemos una disciplina que se ocupa de lo humanamente bueno que tiene en su centro los conceptos de

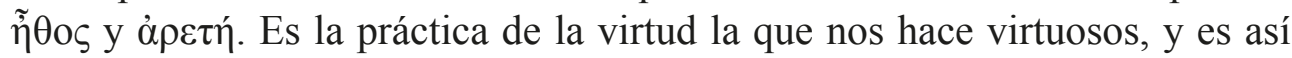
como: "el hombre se convierte en tal solo a través de lo que hace y cómo se comporta, y llega a ser el que es en el sentido de que siendo así se comporta de una determinada manera" (Gadamer, 1977: 384). La prudencia no será un saber fundamentalmente universal, sino un saber de lo concreto, o en todo caso, de la aplicación de lo general a lo concreto. No se asienta en un conocimiento científico y exacto, sino en todo caso en una visión general, un "perfil" (Gadamer, 1977: 384) que se va haciendo más nítido con la educación y la práctica de la virtud. En este sentido, el conocimiento en el terreno de la moral deviene una empresa ética. Además, sin renunciar a su racionalidad, no es, sin embargo, un saber puro ni objetivo. Gadamer ve en la escisión aristotélica entre teoría y praxis el embrión de la distinción entre ciencias del espíritu y ciencias naturales, distinción fundamental en Verdad y Método porque es en 
el contraste entre ambas como se deslinda la comprensión de la explicación científica. Así, afirma ahora:

Por el contrario, frente a esta ciencia "teórica, las ciencias del espíritu forman parte más bien del saber moral. Son "ciencias morales". Su objeto es el hombre y lo que este sabe de sí mismo. Ahora bien, este se sabe a sí mismo como ser que actúa, y el saber que tiene de sí mismo no pretende comprobar lo que es. El que actúa trata más bien con cosas que no siempre son como son, sino que pueden ser también distintas. En ellas descubre que qué punto puede intervenir su actuación: su saber debe dirigir su hacer (Gadamer, 1977: 386).

El actuar moral se aproxima a y es considerado en términos próximos a los de una $\tau \dot{\varepsilon} \chi v \eta$, aunque, claro está, no sean absolutamente idénticos. Se trata del paralelismo que explota Aristóteles al comienzo del libro segundo de su Ética a Nicómaco y que desarrolla en el capítulo 5 del libro VI de la misma obra.

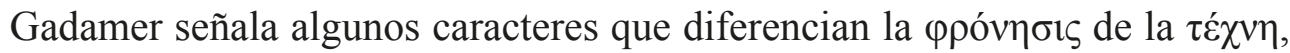
para ganar así conciencia de su especificidad. Estos rasgos los espiga en los contenidos del libro VI de la Ética:

a) Las técnicas se pueden olvidar, la prudencia $n^{22}$. No se pueden olvidar porque en el ámbito de la moral estamos siempre ante la acción, poseemos y aplicamos a la vez el saber. Un artesano tiene un modelo que plasma en un momento concreto en unos materiales, pero el hombre prudente determina a la vez los valores que aplican, aunque tengan un contenido identificable también más allá de un acto concreto. Así, Aristóteles entiende que el juez no es un mero artesano, porque muchas veces la aplicación de la justicia puede consistir en una corrección de la misma. Es lo que sucede en el caso de la

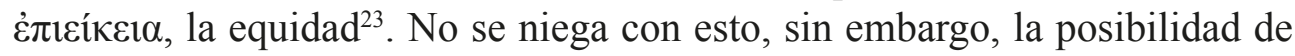
un derecho natural, solo que es flexible.

${ }^{22}$ Gadamer (1977: 388). Otra vez, la observación aristotélica que puso a Heidegger sobre la pista de la especificidad de la $\varphi \rho o ́ v \eta \sigma ı \varsigma$ frente a la destreza artística.

${ }^{23}$ Massini hace un buen repaso de las observaciones sobre el derecho y la hermenéutica en estas páginas de Verdad y Método. Entiende que Gadamer yerra al pensar que la equidad es un componente necesario de toda aplicación de la ley (Massini, 1998: 18). 
b) La relación de medios y fines es diferente en la técnica y en el actuar moral. En la técnica la relación entre medios y fines está dada de antemano, y el conocimiento del arte nos permite encontrar el mejor medio en una circunstancia concreta para ejecutar la obra. Sin embargo, en la prudencia, la ponderación de los medios es una ponderación moral (Gadamer, 1977: 393), y es un momento ineludible de ella el buscar consejo en uno mismo. Adopta la forma de una visión racional de lo correcto que constituye una forma de experiencia o algo muy próximo a ella. ${ }^{24}$

c) La reflexión moral consiste en un "saberse" (Sich-wissen, 394) peculiar. Para calibrarlo pasa revista a las otras facultades que valen como modifica-

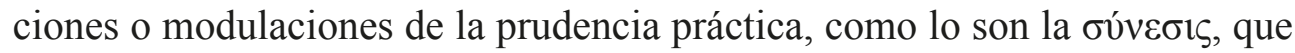
traduce por "comprensión” (Verständnis). La comprensión está dirigida al

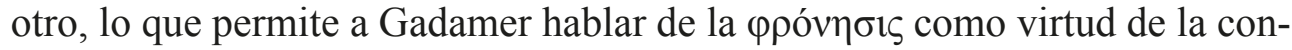
sideración reflexiva. Analiza también el buen juicio, la compasión, y el modo

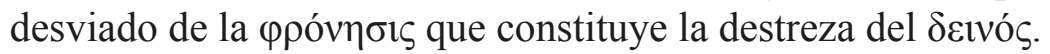

Su conclusión es la siguiente:

El análisis aristotélico se nos muestra como una especie de modelo de los problemas inherentes a la tarea hermenéutica. También nosotros habíamos llegado al convencimiento de que la aplicación no es una parte última y eventual del fenómeno de la comprensión, sino que determina a este desde el principio y en su conjunto. Tampoco aquí la aplicación consistía en relacionar algo general y previo con una situación particular. El intérprete que se confronta con una tradición intenta aplicársela a sí mismo. Pero esto tampoco significa que el texto trasmitido sea para él algo general que pudiera ser empleado posteriormente para una aplicación particular. Por el contrario, el intérprete no pretende otra cosa que comprender este asunto general, el texto, esto es, comprender lo que dice la tradición y lo que hace el sentido y el significado del texto. Y para comprender esto no le es dado querer ignorarse a sí mismo y a la situación hermenéutica concreta en la que se encuentra (Gadamer, 1977: 396).

24 "El saber moral es verdaderamente un saber peculiar. Abarca de una manera particular los medios y los fines y es en esto distinto del saber técnico. Por eso no tiene demasiado sentido distinguir aquí entre saber y experiencia, lo que en cambio conviene perfectamente al saber técnico" (Gadamer, 1977: 394).

SCIO. Revista de Filosofia, n. ${ }^{\circ}$ 18, Julio de 2020, 29-54, ISSN: 1887-9853 
El final de esta excursión por el libro VI de la Ética a Nicómaco acaba en

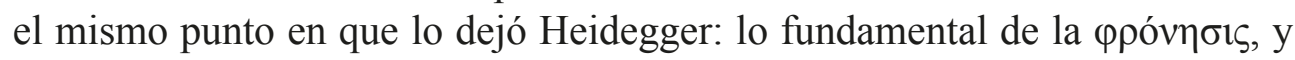
lo que la convierte en un modelo para la comprensión que opera en la hermenéutica es precisamente que consiste en un saber reflexivo, un saberse que se desenvuelve en la acción concreta, al igual que la aplicación en el seno del fenómeno de la interpretación. Gadamer, sin embargo, ha descargado de peso ontológico el recargado análisis heideggeriano, ha eludido las tesis acerca de la naturaleza de la verdad y la custodia del desvelamiento que acontecía en el ejercicio de las virtudes dianoéticas y se ha quedado con la facticidad, la determinación en lo concreto que despliega un tipo especial de conciencia ${ }^{25}$. Ahora bien, todavía no quedan unificados comprensión y actuar ético. En el caso de la hermenéutica, opera la comprensión, en el de la ética, el actuar del hombre prudente. En Verdad y método no se da ningún paso más allá. El caso del saber moral constituye, como afirma el texto que acabamos de citar, un "modelo de los problemas inherentes a la tarea hermenéutica". La situación cambiará en obras posteriores, y la analogía se irá deslizando paulatinamente a una identificación. Esta identificación entre la experiencia hermenéutica y la $\varphi \rho o ́ v \eta \sigma ı \varsigma$ aristotélica corre paralela a un desplazamiento de la comprensión sistemática de la hermenéutica por parte de Gadamer, que poco a poco va distanciándose del modelo dialéctico platónico con el que se daba cuenta de la estructura de la experiencia hermenéutica en Verdad y Método al modelo aristotélico fundado en la retórica. Pasamos a presentar someramente esta evolución.

En La idea del Bien entre Platón y Aristóteles, Gadamer vuelve sobre el tema de la filosofía práctica de Aristóteles. El planteamiento sobre el bien en las éticas aristotélicas enraíza en la crítica de la idea de Bien platónica. Esta crítica aleja su pensamiento de una concepción unívoca del bien, y abre el camino para una concepción diferenciada de la filosofía práctica. Teoría y práctica, sin embargo, no son dos universos estancos y no dependientes. La especificidad de la praxis no es estar separada de la teoría, sino más bien su anclaje en lo particular:

${ }^{25}$ Carmen Segura (2017: 173 ss) insiste en la dimensión política de la comprensión gadameriana

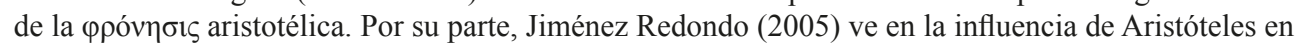

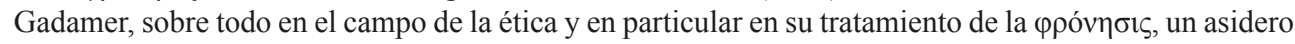
sobre el que se apoyará la crítica de este autor al idealismo hegeliano, Humboldt y el propio Heidegger. 
La concepción aristotélica de una "filosofía práctica" es manifiestamente la consecuencia de su crítica a la idea platónica del Bien, que nosotros hemos tratado. A pesar de ello la separación de la filosofía práctica de la teórica no significa en modo alguno una carencia de relación y de copertenencia en cuanto al contenido. Es más bien una precaución argumentativa metódica, con la que Aristóteles se prohíbe toda incursión en relaciones más universales (Gadamer, 1978: 224) ${ }^{26}$.

Así las cosas, el Estagirita reproduce en la cumbre de su pensamiento el dilema en el que había incurrido también, en cierta medida, su maestro: otorga una prioridad al ideal contemplativo de tipo teórico. El modelo de lo que "está siendo siempre" orienta la propia disposición del ámbito práctico, puesto que es el cultivo de la facultad superior de la razón. Ahora bien, el ser humano es una naturaleza compleja, sometido a los afectos, y habrá de desarrollar disposiciones estables, hábitos que le permitan conducir su vida de manera virtuosa. Claro está que, en razón de su objeto, la razón teórica es superior. Sin embargo, como actividades, ambas son excelencias:

Uno no tiene el derecho a absolutizar la ubicación del ideal de vida teórico por encima del político-práctico. Pues precisamente la posibilidad de vida teórica es -como Aristóteles lo sabe tan bien como Platón- una limitada y condicionada para el hombre. Él no puede dedicarse perdurablemente e ininterrumpidamente al puro ver pensante, puesto que él es precisamente de naturaleza compuesta. Pero con ello, la relación de ambos ideales de vida no es, desde el punto de vista de la filosofía práctica, de tal clase que la completa felicidad de la vida práctica no fuera también un más alto. Cierto, Aristóteles lo llama $\delta \varepsilon v ́ \tau \varepsilon \rho o \varsigma$, es decir, él es un segundo-mejor. Pero también este es un mejor, es decir, una realización de la eudaimonía (Gadamer, 1978: 226).

La pugna entre política y teoría, entre teoría y praxis, en definitiva, puede

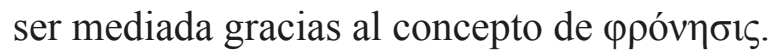

\footnotetext{
${ }^{26}$ No conozco el nombre del autor de la traducción española del texto, que circula en repositorios de internet sin indicación alguna de autoría.
} 
En su entrevista con Ricardo Dottori, Gadamer pasa revista a su relación con Heidegger en los tiempos de Marburgo. Señala la profunda impresión que le produjo El ser y el tiempo, y cómo encuentra una importante limitación en la potente maquinaria existencial heideggeriana a la hora de pensar al otro. Centrado en la conciencia moral, Heidegger no desarrolla suficientemente el concepto de "ser-con" y no consigue elaborar un pensamiento adecuado de la

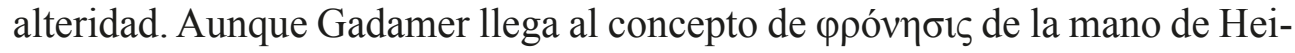
degger, su modo de desarrollarlo muestra unas líneas de interés diferentes a las de su maestro. Entronca decididamente su pensamiento con una comprensión de la experiencia hermenéutica como relación con el otro en el seno del

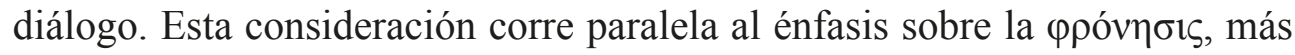
centrada en el objeto que en la articulación de la experiencia hermenéutica. Como formas del voũ $\zeta$, teoría y práxis no pueden oponerse (Gadamer, 2010: 40). El voũ s es lo más universal y al mismo tiempo lo más concreto, y la prudencia se orienta al actuar correcto, sin poder perder para ello su referencia al fin. En cualquier caso, la $\theta \varepsilon \omega \rho i ́ \alpha$ es la más alta forma de la $\pi \rho \alpha ́ \xi \xi \varsigma$ (Gadamer, 2010: 41).

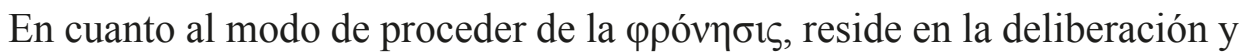
la elección. Aunque deliberación y elección se dan en el individuo moral en un proceso interior, no dejan de ser procesos de ejercicio dialogal cuya matriz

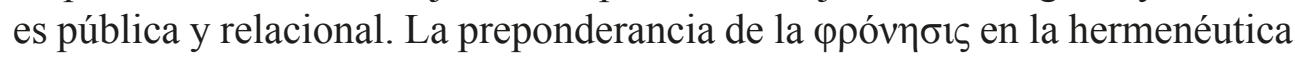
gadameriana le va llevando a situar en el centro, en paralelo, como decíamos, una visión de la interpretación como ejercicio dialéctico y fundamentalmente retórico:

La retórica, o como quiera que llamemos al arte del discurso o del persuadir, no consiste, como se ha creído durante siglos, en un conjunto de reglas que, siguiéndolas, lograremos alcanzar la victoria en las discusiones. El arte del discurso, o del persuadir, consiste más bien en la capacidad innata, que sin embargo podemos perfeccionar y desarrollar, de lograr comunicar efectivamente, y por tanto persuadir de lo verdadero a aquellos que tenemos enfrente, aun cuando esto resulte imposible en la forma acostumbrada de demostración. Se trata de hablar a los afectos, o a las pasiones del alma, y por eso el Libro II [sc.: de la Retórica de Aristóteles] trata de las pasiones, pero no para engañar o por la mera ventaja personal, sino para 
lograr hacer aparecer aquello verdadero de lo que estamos convencidos, o estamos en posesión, y que sin embargo no acierta a mostrarse como tal en la manifestación de la demostración. Por esto Aristóteles llama al campo de la retórica el dominio del sícós, o de lo verosímil: dado que se trata de algo verdadero que se nos muestra en el discurso y que podría también ser no verdadero, no hay certeza absoluta o garantía absoluta de que se trate de lo verdadero. Esto es precisamente lo que sucede en la situación comunicativa de todos los días, donde debemos hacer "valer nuestras propias razones", pero no en el sentido de que debemos engañar a los demás, sino en el sentido de que debemos tener éxito en hacer aparecer claras a los demás las que entendemos que son nuestras razones, es decir, que aquello de lo que estamos convencidos es lo verdadero (Gadamer, 2010: 59).

Así entendida, la retórica se convierte en arte del dialogar y convencer, de comunicar y persuadir de lo correcto y lo verdadero. En el fondo, el distanciamiento de la matriz platónica ubicada en la lógica de la pregunta y la respuesta y en el diálogo es más aparente de lo que se pudiera creer porque, como hemos visto, Gadamer apuesta por una concepción dialógica de la retórica aristotélica. No es el arte de vencer en las discusiones, sino el de convencer. No es una destreza desligada de la verdad, sino una herramienta para descubrirla que está al servicio de ella. Se mueve en la relación con los demás, tiene en cuenta las pasiones y los condicionamientos de cualquier naturaleza, renuncia a los absolutos para descender a las situaciones comunicativas cotidianas de todo tipo. La necesidad de poder comprender y explicar nuestro proceder en las diferentes situaciones en que nos podamos encontrar es el campo en el que se produce la unificación entre argumentación retórica y razón práctica como

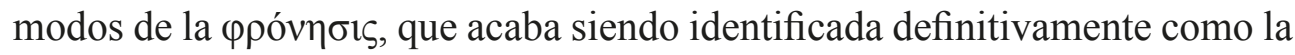
forma de la experiencia hermenéutica:

La retórica pertenece fundamentalmente a la phronesis, es una forma de la phronesis o de la sabiduría práctica, al igual que la ética (Gadamer, 2010: 64). 
La retórica se vuelve así una dimensión fundamental de la experiencia hermenéutica y una manera de entender la sabiduría ${ }^{27}$. Gadamer puede presentarse de este modo como heredero de la antigua defensa de la retórica por parte de Vico, y su postulación como un modelo de saber alternativo al propugnado por el cientificismo. La retórica así entendida viene a coincidir con la totalidad del proyecto humanista y deviene en un ejercicio de la comprensión que abarca a todas las denominadas ciencias del espíritu. Por eso podía la primera parte de Verdad y Método presentar la hermenéutica como la culminación de una larga tradición en el contexto del pensamiento occidental.

Ciertamente, la reivindicación de la retórica como un saber comprehensivo coextensivo con el humanismo no debe olvidar que el soberbio edificio hermenéutico que parte de ella no se elaboró solamente desde la retórica aristotélica, sino también y tal vez fundamentalmente a partir de la tradición hermenéutica posterior grecorromana de Cicerón, Quintiliano y Dionisio de Halicarnaso, entre otros.

En la dirección de una hermenéutica fundada en la retórica avanzarán tanto la idea de la retórica de Perelmann, como la del propio Ricoeur en Sí mismo como otro y Teoría de la interpretación. Sus semejanzas y diferencias con la concepción hermenéutica gadameriana son interesantes. Pero esto sería en todo caso objeto de un trabajo posterior (Soto, 2001: 50).

\section{REFERENCIAS BIBLIOGRÁFICAS}

Beuchot, M. (2007). Retórica y hermenéutica en Aristóteles. Nova Tellus, 25(1), 217-234.

Bertorello, A. (2000). Hermenéutica de la vida y filosofía en el escrito de Heidegger. Interpretaciones fenomenológicas de Aristóteles. Agora. Papeles de filosofia (19), 169-181.

${ }^{27}$ En sus discusiones con Derrida reflejadas en la entrevista con Ricardo Dottori, este le imputaba que al dar un énfasis a la retórica esta se convierte en un ejercicio de la voluntad de poder nietzscheana. Gadamer responderá que no se trata tanto de la voluntad de poder, sino de la voluntad de verdad (Gadamer, 2010: 64). 
De Haro, V. (2002) La mimesis de Aristoteles desde la hermenéutica de Paul Ricoeur. Topicos (23), 49-70.

Heidegger, M. (1971). El ser y el tiempo. México: FCE.

Heidegger, M. (1992). Platon: Sophistes. Frankfurt am Main: Vittorio Klostermann.

Heidegger, M. (2002). Interpretaciones fenomenológicas de Aristóteles (Indicación de la situación hermenéutica). Informe Natorp. Madrid: Trotta.

Gadamer, H. G. (1977). Verdad y Método I. Salamanca: Ediciones Sígueme.

Gadamer, H. G. (1978). Die Idee des Guten zwischen Plato und Aristoteles. En Gesammelte Werke Band, 7. J. C. Mohr. Tübingen 1991, 128-227.

Gadamer, H. G. (1998). Verdad y Método II. Salamanca: Ediciones Sígueme.

Gadamer, H. G. (2003). Los caminos de Heidegger. Barcelona: Herder.

Gadamer, H. G. (2003). La teología de Marburgo. En H. G. Gadamer, Los caminos de Heidegger. Barcelona: Herder.

Gadamer, H. G. (2010). El último Dios. La lección del siglo XX. Un diálogo filosófico con Riccardo Dottori. Barcelona: Antropos-cuajimalpa.

Jiménez Redondo, M. (2005). Gadamer sobre el concepto aristotélico de phrónesis. ENDOXA: Series Filosóficas (20), 295-323.

Massini, C. (1988). Hermenéutica clásica y objetivismo jurídico. Seminarios de Filosofia (11), 11-38.

Oñate, T. (2007). Gadamer y Aristóteles. la actualidad de la hermenéutica. En T. Oñate, Gadamer y las humanidades, vol. I, Madrid.

Ricoeur, P. (1980). La Metáfora Viva. Madrid: Cristiandad.

Ricoeur, P. (1987). Tiempo y narración, vol. I. Madrid: Cristiandad.

Segura, C. (2002). Hermenéutica de la vida humana. En torno al Informe Natorp de Heidegger. Madrid: Trotta.

Segura, C. (2007). Heidegger y la metafisica. Análisis críticos. Madrid: Creative commons.

Segura, C. (2015). Heidegger en torno a Aristóteles. Una mirada fenomenológico-hermenéutica. Contrastes. Revista Internacional de Filosofía, 2(XX), 231-249. 
Segura, C. (2017). La lectura gadameriana de la filosofía práctica de Aristóteles. Constitución de una hermenéutica ontológica y política. Pensamiento, 275(73).

Soto, D. (2001). Aristóteles y hermenéutica. Estudios de Filosofia (23), febrero. Universidad de Antioquia.

Volpi, F. (2012). Heidegger y Aristóteles. México: FCE.

Volpi, F. (1976). Heidegger e Brentano. Padua: Cedam. 